\title{
The Macroeconomic Effects of Large-Scale Asset Purchase Programs
}

\author{
Han Chen, \\ University of Pennsylvania; \\ Vasco Curdia, \\ Federal Reserve Bank of San Francisco; \\ Andrea Ferrero, \\ Federal Reserve Bank of New York
}

October 2012

Working Paper 2012-22

http://www.frbsf.org/publications/economics/papers/2012/wp12-22bk.pdf

The views in this paper are solely the responsibility of the authors and should not be interpreted as reflecting the views of the Federal Reserve Bank of San Francisco or the Board of Governors of the Federal Reserve System. 


\title{
The Macroeconomic Effects of Large-Scale Asset
}

\section{Purchase Programs*}

\author{
Han Chen $^{\dagger} \quad$ Vasco Cúrdia ${ }^{\ddagger} \quad$ Andrea Ferrero ${ }^{\S}$
}

October 24, 2012

\begin{abstract}
We simulate the Federal Reserve second Large-Scale Asset Purchase program in a DSGE model with bond market segmentation estimated on U.S. data. GDP growth increases by less than a third of a percentage point and inflation barely changes relative to the absence of intervention. The key reasons behind our findings are small estimates for both the elasticity of the risk premium to the quantity of long-term debt and the degree of financial market segmentation. Absent the commitment to keep the nominal interest rate at its lower bound for an extended period, the effects of asset purchase programs would be even smaller.
\end{abstract}

Keywords: quantitative easing, zero lower bound, unconventional monetary policy

JEL codes: E43, E44, E52, E58

*This paper was prepared for the conference "Learning the Lessons from QE and Other Unconventional Monetary Policies," that took place at Bank of England on November 17-18, 2011. Special thanks to Andrew Scott (the editor) and an anonymous referee for their extremely valuable suggestions, Richard Harrison for his discussion at the conference, and the conference participants for their comments. We have also benefited from comments by Hal Cole, Frank Diebold, Stefano Eusepi, John Fernald, Keith Kuester, James Nason, Ed Nelson, Ricardo Reis, Glenn Rudebusch, Frank Schorfheide, Eric Swanson, Michael Woodford, and seminar participants at the University of Pennsylvania, Federal Reserve Banks of New York, Philadelphia and San Francisco, University of California Santa Cruz and the European Economic Association 2011 Meetings in Oslo. The views expressed in this paper are those of the authors and do not necessarily reflect the position of the Federal Reserve Bank of New York, the Federal Reserve Bank of San Francisco or the Federal Reserve System.

${ }^{\dagger}$ University of Pennsylvania

${ }^{\ddagger}$ Corresponding Author, Federal Reserve Bank of San Francisco, 101 Market Street, MS 1130, San Francisco, CA 94105, email: vasco.curdia@sf.frb.org.

$\S$ Federal Reserve Bank of New York 


\section{The Macroeconomic Effects of LSAP Programs}

\section{Introduction}

In response to the recent financial crisis, the major central banks around the world have engaged in multiple rounds of large scale asset purchase (LSAP) programs, typically financed with the creation of excess reserves. The Federal Reserve purchased a total of $\$ 1.75$ trillion in agency debt, mortgage-backed securities and Treasuries starting in early 2009, followed by a second Treasury-only program in the fall of $2010 .^{1}$ Also in early 2009, the Bank of England set up an asset purchase facility whose size is, at the time of this writing, $£ 275$ billion, approximately equivalent to $\$ 445$ billion at the current exchange rate. The European Central Bank initiated purchases of up to $€ 60$ billion (almost $\$ 80$ billion) in Euro area covered bonds in mid-2009. In October of 2010, the Bank of Japan unveiled a $¥ 5$ trillion (approximately $\$ 62$ billion) asset purchase program, which has been progressively increased to $¥ 70$ trillion at the time of this writing.

The objective of the various LSAP programs, often referred to as "Quantitative Easing" (or QE), is to support aggregate economic activity in periods when the traditional instrument of monetary policy (the short-term nominal interest rate) is not available due to the zero bound constraint. The general idea is that asset purchases operate directly on different segments of the yield curve, reducing rates at different maturities while the short-term rate is at zero.

Several papers find evidence that LSAP programs have indeed been effective in reducing long-term rates. For example, Gagnon et al. (2011) estimate that the first round of asset purchases by the Federal Reserve lowered the ten-year Treasury yield by 58 basis points $(\mathrm{bp}) .^{2}$

\footnotetext{
${ }^{1}$ In September of 2011 , the Fed announced an additional $\$ 400$ billion program, this time as a pure swap between short-term and long-term assets not involving the creation of additional reserves.

${ }^{2}$ A selected sample of other estimates include $13 \mathrm{bp}$ in Hamilton and Wu (2010), 39 bp in Doh (2010), 45 bp in D'Amico and King (2010), and 107 bp in Neely (2010). Krishnamurthy and Vissing-Jorgensen (2011) find that LSAP II reduced the ten-year yield by about $16 \mathrm{bp}$. See more details in Table 1.
} 


\section{The Macroeconomic EfFects of LSAP Programs}

Yet, agreement on the effectiveness of LSAP programs in supporting the macroeconomy is far from universal. From a theoretical perspective, LSAP programs were criticised before their implementation, based on some version of the irrelevance result in Wallace (1983). Quantitative easing of this type is also completely ineffective in the baseline New Keynesian model of Eggertsson and Woodford (2003). In this framework, injecting reserves in exchange for longer term securities is a neutral operation. To the extent that market participants take full advantage of arbitrage opportunities, LSAP programs should have no effect on real economic outcomes. Cúrdia and Woodford (2011) extend this result to a New Keynesian model with credit frictions. If households perceive the assets purchased (such as short-term government bonds) as equivalent to reserves, again LSAP programs have no effect on the macroeconomy. ${ }^{3}$ Ex-post, the criticism has continued due to the difficulty of identifying empirically the effects of asset purchases from other macroeconomic forces (e.g. Cochrane, 2011).

In this paper, we estimate the effects of LSAP on macroeconomic variables in a dynamic stochastic general equilibrium (DSGE) model with segmented asset markets. General equilibrium effects are at the heart of Wallace's irrelevance theorem. By going beyond the effects of asset purchases on interest rates, we can evaluate the extent of the criticisms against this type of programs. At the same time, we want to give LSAP programs a chance. We introduce limits to arbitrage and market segmentation in a simple form that encompasses frictionless financial markets. Therefore, our strategy is to identify the degree of segmentation - and ultimately the effectiveness of asset purchases on macroeconomic activity - directly from the data, without assuming a priori that LSAP programs are bound to fail.

To implement this approach, we augment a standard DSGE model with nominal and real

\footnotetext{
${ }^{3}$ Asset purchase programs may be an effective tool to boost the economy if the government buys securities that are not equivalent to reserves, either because not all households can invest in those assets or because financial frictions impair investment. Recent research along these lines, such as Cúrdia and Woodford (2011), Del Negro et al. (2011) and Gertler and Karadi (2011), has mostly focused on private credit markets. Here, instead, we study frictions that rationalise a role for government purchases of long-term bonds.
} 


\section{The Macroeconomic EfFects of LSAP Programs}

rigidities, along the lines of Christiano et al. (2005) and Smets and Wouters (2007), with segmented bond markets. In particular, we follow Andrés et al. (2004, henceforth ALSN) and assume that investors have heterogeneous preferences for assets of different maturities (a "preferred habitat" motive, similar to Vayanos and Vila, 2009). We do not model the details of why assets of different maturities are imperfect substitutes. Rather, we postulate that this type of market segmentation exists and estimate the importance of this friction for the transmission mechanism of monetary policy.

The form of asset market segmentation that we use in this paper implies that the longterm interest rate matters for aggregate demand distinctly from the expectation of shortterm rates. In this world, even if the short-term rate is constrained by the zero lower bound (ZLB) for a long period of time, monetary policy can still be effective by directly influencing current long-term rates. In addition, we assume that the risk premium that arises in the model as a consequence of transaction costs is a positive function of the supply of long-term Treasury securities. This assumption captures, in reduced form, the notion that asset purchase programs are most effective in flattening the yield curve by reducing the risk premium (Gagnon et al., 2011).

We estimate the model on U.S. data with standard Bayesian methods for the post-war sample, including the recent years. Our main experiment is a counterfactual evaluation of what would have happened to output, inflation and the other macroeconomic variables in the absence of LSAP programs. ${ }^{4}$

First, we calibrate the size of the asset purchase program to match a $\$ 600$ billion reduction of long-term debt in the hands of the private sector, as announced in the U.S. at the time of LSAP II. At the same time, we consider that the central bank announces the commitment to hold the interest rate at the ZLB for four quarters. ${ }^{5}$ The posterior median effect on GDP

\footnotetext{
${ }^{4}$ These simulations present us with the key challenge of incorporating the zero bound of nominal interest rates. We deal with this problem using the techniques developed in Cúrdia and Woodford (2011).

${ }^{5}$ This assumption is consistent with the "extended period" language in the FOMC statements at the time
} 


\section{The Macroeconomic Effects of LSAP Programs}

growth is an increase of $0.13 \%$ (annualised), while the posterior median inflation increase is $3 \mathrm{bp}$ (annualised). The corresponding effect on the level of GDP is estimated to be very long lasting - six years after the start of the program the level of GDP is still $0.07 \%$ above the path that would have prevailed in the absence of the LSAP program.

Counterfactual simulations suggest that the commitment to hold the short-term nominal interest rate at the ZLB increases the response of real activity and inflation roughly by factors of three and two, respectively, and introduces upward skewness in the uncertainty surrounding the median estimates. Furthermore, the boost from the commitment to the ZLB is increasingly larger with the length of such a commitment. Overall, in our model, the effects of LSAP II are slightly smaller - and considerably more uncertain - than a 25 bp cut in the short-term rate.

These results suggest that the effects of LSAP programs on macroeconomic variables, such as GDP and inflation, are likely to be modest. In the technical appendix, we consider several robustness exercises and find that the effects on GDP growth are unlikely to exceed a third of a percentage point. The inflationary consequences of asset purchase programs are consistently very small throughout all scenarios considered. As a comparison, using the FRB/US model, Chung et al. (2011) find that LSAP II induced a reduction in the risk premium of only $20 \mathrm{bp}$ but increased the level of GDP by about $0.6 \%$ and the inflation rate by $0.1 \%$. Baumeister and Benati (2011), using a VAR with time-varying coefficients, consider a change in the term premium of $60 \mathrm{bp}$ and estimate a median increase in GDP growth of $3 \%$ and on inflation of $1 \%$. Our results are therefore more moderate than in the existing literature, especially compared to the VAR methodology. Importantly, our results only touch upon the positive dimension of LSAP programs. Harrison (2010) evaluates the macroeconomic consequences of the optimal amount of asset purchases in a version of this model without capital. His findings are consistent with ours in the sense that asset purchases of LSAP II and the market expectations as implied in surveys of private forecasters. 


\section{The Macroeconomic Effects of LSAP Programs}

can improve aggregate welfare, but their quantitative relevance appears to be limited.

Our results do not depend on whether asset purchases are financed via reserves or sales of short-term debt, to the extent that these two assets are close to perfect substitutes. Therefore, according to our model, the effects of the Federal Reserve's last round of asset purchases (also known as "Operation Twist Again") should be in line with the estimates from LSAP II after controlling for the scale factor and for any differences in the duration of the commitment to the zero interest rate.

The rest of the paper proceeds as follows. The next section presents the model. Section 3 discusses the data, the estimation of the model, some basic analysis of parameter estimates and an evaluation of how the model explains the level and slope of the term structure of interest rates. We discuss the LSAP simulation in Section 4. Finally, section 5 concludes. The companion technical appendix presents additional details on the model equations and steady state, data, implementation of the zero lower bound commitment, additional robustness exercises and some diagnostics on shock and variance analysis with respect to the components of the yield curve.

\section{Model}

Two types of households, unrestricted (denoted by $u$ ) and restricted (denoted by $r$ ), populate the economy and supply differentiated labour inputs. Competitive labour agencies combine these inputs into a homogeneous composite. Competitive capital producers transform the consumption good into capital. Monopolistic competitive firms hire the labour composite and rent capital to produce intermediate goods. Competitive final goods producing firms package intermediate goods into a homogeneous consumption good. Finally, the government sets monetary and fiscal policy. 


\section{The Macroeconomic Effects of LSAP Programs}

\subsection{Households}

The key modification relative to a standard medium-scale DSGE model (Christiano et al., 2005; Smets and Wouters, 2007) is the introduction of segmentation and transaction costs in bond markets, as in ALSN.

A continuum of measure one of households populate the economy. Household $j=u, r$ enjoys consumption $C_{t}^{j}$ (relative to productivity $Z_{t}$, as in An and Schorfheide, 2007) and dislikes hours worked $L_{t}^{j}{ }^{6}{ }^{6}$ Households supply differentiated labour inputs indexed by $i$ but perfectly share consumption risk within each group. The life-time utility function for a generic households $j$ is

$$
\mathbb{E}_{t} \sum_{s=0}^{\infty} \beta_{j}^{s} b_{t+s}^{j}\left[\frac{1}{1-\sigma_{j}}\left(\frac{C_{t+s}^{j}}{Z_{t+s}}-h \frac{C_{t+s-1}^{j}}{Z_{t+s-1}}\right)^{1-\sigma_{j}}-\frac{\varphi_{t+s}^{j}\left(L_{t+s}^{j}(i)\right)^{1+\nu}}{1+\nu}\right]
$$

where $\beta_{j} \in(0,1)$ is the individual discount factor, $b_{t}^{j}$ is a preference shock, $\sigma_{j}>0$ is the coefficient of relative risk aversion, $h \in(0,1)$ is the habit parameter, $\nu \geq 0$ is the inverse elasticity of labour supply and $\varphi_{t}^{j}$ is a labour supply shock. ${ }^{7}$ The preference and labour supply shocks both follow stationary AR(1) processes in logs.

Two types of bonds exist. Short-term bonds $B_{t}$ are one-period securities purchased at time $t$ that pay a nominal return $R_{t}$ at time $t+1$. Following Woodford (2001), long-term bonds are perpetuities that $\operatorname{cost} P_{L, t}$ at time $t$ and pay an exponentially decaying coupon $\kappa^{s}$ at time $t+s+1$, for $\kappa \in(0,1] .{ }^{8}$ We abstract from money and consider the limit of a cashless economy as in Woodford (1998).

\footnotetext{
${ }^{6}$ We express utility as a function of de-trended consumption to ensure the existence of a balanced growth path with constant relative risk aversion preferences. Imposing log-utility of consumption may be an excessively restrictive assumption in our model which is mainly concerned about asset pricing.

${ }^{7}$ We allow for heterogeneity in preference shocks, discount factors and coefficient of relative risk aversions because these factors affect the household's consumption-saving decisions and financial market segmentation directly influences these optimality conditions. As such, this heterogeneity can potentially influence the simulation results in a substantial way.

${ }^{8}$ If $\kappa=1$, this security is a consol.
} 


\section{The Macroeconomic Effects of LSAP Programs}

The fraction $\omega_{u}$ of unrestricted households trade in both short-term and long-term government bonds. Unrestricted households, however, pay a transaction cost $\zeta_{t}$ per-unit of long-term bond purchased. This transaction cost is paid to a financial intermediary as a fee for its service. The financial intermediary distributes its profits, whose per-capita nominal value is $\mathcal{P}_{t}^{f i}$, as dividends to all shareholders (regardless of type). The remaining fraction of the population $\omega_{r}=1-\omega_{u}$ consists of restricted households who only trade in long-term bonds but pay no transaction costs. ${ }^{9}$

The flow budget constraint differs depending on whether the household belongs to the unrestricted or restricted group. For an unrestricted household that can trade both short and long-term bonds, we have

$P_{t} C_{t}^{u}+B_{t}^{u}+\left(1+\zeta_{t}\right) P_{L, t} B_{t}^{L, u} \leq R_{t-1} B_{t-1}^{u}+\sum_{s=1}^{\infty} \kappa^{s-1} B_{t-s}^{L, u}+W_{t}^{u}(i) L_{t}^{u}(i)+\mathcal{P}_{t}+\mathcal{P}_{t}^{c p}+\mathcal{P}_{t}^{f i}-T_{t}^{u}$

For a restricted household that can only trade in long-term securities but does not pay transaction costs, we have

$$
P_{t} C_{t}^{r}+P_{L, t} B_{t}^{L, r} \leq \sum_{s=1}^{\infty} \kappa^{s-1} B_{t-s}^{L, r}+W_{t}^{r}(i) L_{t}^{r}(i)+\mathcal{P}_{t}+\mathcal{P}_{t}^{c p}+\mathcal{P}_{t}^{f i}-T_{t}^{r}
$$

In equations $(2.2)$ and $(2.3), P_{t}$ is the price of the final consumption good, $W_{t}^{j}(i)$ is the wage set by a household of type $j=\{u, r\}$ who supplies labour of type $i, \mathcal{P}_{t}$ and $\mathcal{P}_{t}^{c p}$ are profits from ownership of intermediate goods producers and capital producers respectively, and $T_{t}^{j}$ are lump-sum taxes. ${ }^{10}$

One advantage of assuming that the entire stock of long-term government bonds consists of perpetuities is that the price in period $t$ of a bond issued $s$ periods ago $P_{L-s, t}$ is a function

\footnotetext{
${ }^{9}$ We discuss in more details the implications of transaction costs and bond market segmentation in sections 2.6.1 and 2.6.2 below.

${ }^{10}$ Each household receives the same dividend from intermediate goods and capital producers and pays the same amount of lump-sum taxes.
} 


\section{The Macroeconomic Effects of LSAP Programs}

of the coupon and the current price, $P_{L, t}$. In the technical appendix, we show how we can write the budget constraints for the two types of households recursively as a function of the price of the bond in period $t$ and the yield to maturity of the bond, $R_{L, t}$.

Household $j$ consumption-saving decisions are the result of the maximisation of (2.1) subject to (2.2) if $j=u$ or $(2.3)$ if $j=r$. See the technical appendix for details and section 2.6 for some discussion.

\subsection{1 labour agencies and wage setting decision}

Perfectly competitive labour agencies combine differentiated labour inputs into a homogenous labour composite $L_{t}$ according to the technology

$$
L_{t}=\left[\int_{0}^{1} L_{t}(i)^{\frac{1}{1+\lambda_{w}}} d i\right]^{1+\lambda_{w}}
$$

where $\lambda_{w} \geq 0$ is the steady state wage markup.

Profit maximisation gives the demand for the $i^{\text {th }}$ labour input

$$
L_{t}(i)=\left[\frac{W_{t}(i)}{W_{t}}\right]^{-\frac{1+\lambda w}{\lambda_{w}}} L_{t}
$$

From the zero profit condition for labour agencies, we obtain an expression for the aggregate wage index $W_{t}$ as a function of the wage set by the $i^{t h}$ household

$$
W_{t}=\left[\int_{0}^{1} W_{t}(i)^{-\frac{1}{\lambda w}} d i\right]^{-\lambda_{w}}
$$

Households are monopolistic suppliers of differentiated labour inputs $L_{t}(i)$ and set wages on a staggered basis (Calvo, 1983) taking the demand for their input as given. In each period, the probability of resetting the wage is $1-\zeta_{w}$, while with the complementary probability the wage is automatically increased by the steady state rates of inflation (П) and of productivity 
growth $\left(e^{\gamma}\right)$,

$$
W_{t+s}^{j}(i)=\left(\Pi e^{\gamma}\right)^{s} \tilde{W}_{t}^{j}(i),
$$

for $s>0$, where $\tilde{W}_{t}^{j}(i)$ is the wage chosen at time $t$ in the event of an adjustment. A household of type $j$ that can reset the wage at time $t$ chooses $\tilde{W}_{t}^{j}(i)$ to maximise

$$
\mathbb{E}_{t} \sum_{t=0}^{\infty}\left(\beta_{j} \zeta_{w}\right)^{s}\left[\Xi_{t+s}^{j, p}\left(\Pi e^{\gamma}\right)^{s} \tilde{W}_{t}^{j}(i) L_{t+s}^{j}(i)-\frac{\varphi_{t+s}^{j}\left(L_{t+s}^{j}(i)\right)^{1+\nu}}{1+\nu}\right]
$$

where $\Xi_{t}^{j, p}$ is the marginal utility of consumption in nominal terms, subject to (2.4) and (2.5). The technical appendix presents the first order condition for this problem.

\subsection{Capital Producers}

Competitive capital producers make investment decisions, choose the utilisation rate and rent capital to intermediate good producing firms. By choosing the utilisation rate $u_{t}$, capital producers end up renting in each period $t$ an amount of "effective" capital equal to

$$
K_{t}=u_{t} \bar{K}_{t-1},
$$

Capital producers accumulate capital according to

$$
\bar{K}_{t}=(1-\delta) \bar{K}_{t-1}+\mu_{t}\left[1-S\left(\frac{I_{t}}{I_{t-1}}\right)\right] I_{t},
$$

where $\delta \in(0,1)$ is the depreciation rate, $\mu_{t}$ is an investment-specific technology shock that follows a stationary $\mathrm{AR}(1)$ process in $\operatorname{logs}$ and $S(\cdot)$ is the cost of adjusting investment (with $S^{\prime}(\cdot) \geq 0$ and $\left.S^{\prime \prime}(\cdot)>0\right) \cdot{ }^{11}$

\footnotetext{
${ }^{11}$ Furthermore, we assume that $S\left(e^{\gamma}\right)=S^{\prime}\left(e^{\gamma}\right)=0$.
} 


\section{The Macroeconomic EfFects of LSAP Programs}

Capital producers discount future profits at the marginal utility of the average shareholder

$$
\Xi_{t+s}^{p} \equiv \omega_{u} \beta_{u}^{s} \Xi_{t+s}^{u, p}+\omega_{r} \beta_{r}^{s} \Xi_{t+s}^{r, p}
$$

This variable is the appropriate discount factor of future dividends because ownership of capital producing firms is equally distributed among all households. ${ }^{12}$ Capital producers maximise the expected discounted stream of dividends to their shareholders

$$
\mathbb{E}_{t} \sum_{s=0}^{\infty} \Xi_{t+s}^{p}\left[R_{t+s}^{k} u_{t+s} \bar{K}_{t+s-1}-P_{t+s} a\left(u_{t+s}\right) \bar{K}_{t+s-1}-P_{t+s} I_{t+s}\right],
$$

subject to the law of motion of capital (2.6), where $R_{t}^{k}$ is the return per unit of effective capital. Note that we assume that utilisation subtracts real resources measured in terms of the consumption good, $a\left(u_{t}\right) \bar{K}_{t-1} \cdot{ }^{13}$

\subsection{Final Goods Producers}

Perfectly competitive final goods producers combine differentiated intermediate goods $Y_{t}(f)$, supplied by a continuum of firms $f$ of measure 1, into a homogeneous good $Y_{t}$ according to the technology

$$
Y_{t}=\left[\int_{0}^{1} Y_{t}(f)^{\frac{1}{1+\lambda_{f}}} d f\right]^{1+\lambda_{f}}
$$

where $\lambda_{f} \geq 0$ is the steady state price markup. The resulting demand for the $f^{t h}$ intermediate good is

$$
Y_{t}(f)=\left[\frac{P_{t}(f)}{P_{t}}\right]^{-\frac{1+\lambda_{f}}{\lambda_{f}}} Y_{t}
$$

\footnotetext{
${ }^{12}$ The same consideration applies below to intermediate goods producers.

${ }^{13}$ As in Christiano et al. (2009), we choose an implicit functional form for $a\left(u_{t}\right)$ such that $u=1$ in steady state and $a(1)=0$.
} 


\section{The Macroeconomic Effects of LSAP Programs}

From the zero profit condition for intermediate goods producers, we obtain an expression for the aggregate price index $P_{t}$ as a function of the price set by the $f^{t h}$ intermediate good producer

$$
P_{t}=\left[\int_{0}^{1} P_{t}(f)^{-\frac{1}{\lambda_{f}}} d f\right]^{-\lambda_{f}}
$$

\subsection{Intermediate Goods Producers}

A continuum of measure one of monopolistic competitive firms combine rented capital and hired labour to produce intermediate goods according to a standard Cobb-Douglas technology

$$
Y_{t}(f)=K_{t}(f)^{\alpha}\left(Z_{t} L_{t}(f)\right)^{1-\alpha}
$$

where $Z_{t}$ is a labour-augmenting technology process which evolves according to

$$
\log \left(\frac{Z_{t}}{Z_{t-1}}\right)=\left(1-\rho_{z}\right) \gamma+\rho_{z} \log \left(\frac{Z_{t-1}}{Z_{t-2}}\right)+\epsilon_{z, t}
$$

Cost minimisation yields an expression for the marginal cost which only depends on aggregate variables

$$
M C(f)_{t}=M C_{t}=\frac{\left(R_{t}^{k}\right)^{\alpha} W_{t}^{1-\alpha}}{\alpha^{\alpha}(1-\alpha)^{1-\alpha} Z_{t}^{1-\alpha}} .
$$

Intermediate goods producers set prices on a staggered basis (Calvo, 1983). In each period, a firm can readjust prices with probability $1-\zeta_{p}$ independently of previous adjustments. We depart from the basic formulation of staggered price setting in assuming the firms that

cannot adjust in the current period index their price to the steady state inflation rate $\Pi$. The problem for a firm that can adjust at time $t$ is to choose the price $\tilde{P}_{t}(f)$ that maximises

$$
\mathbb{E}_{t} \sum_{s=0}^{\infty} \zeta_{p}^{s} \Xi_{t+s}^{p}\left[\tilde{P}_{t}(f) \Pi^{s}-\lambda_{f, t+s} M C_{t+s}\right] Y_{t+s}(f)
$$




\section{The Macroeconomic Effects of LSAP Programs}

subject to (2.7) conditional on no further adjustments after $t$, where $\lambda_{f, t}$ is a goods markup shock that follows a stationary $\mathrm{AR}(1)$ process in logs.

\subsection{Government Policies}

The central bank follows a conventional feedback interest rate rule similar to Taylor (1993), amended to include interest rate smoothing (Clarida et al., 2000) and using the growth rate of output instead of the output gap (Justiniano et al., 2011)

$$
\frac{R_{t}}{R}=\left(\frac{R_{t-1}}{R}\right)^{\rho_{m}}\left[\left(\frac{\Pi_{t}}{\Pi}\right)^{\phi_{\pi}}\left(\frac{Y_{t} / Y_{t-4}}{e^{4 \gamma}}\right)^{\phi_{y}}\right]^{1-\rho_{m}} e^{\epsilon_{m, t}}
$$

where $\Pi_{t} \equiv P_{t} / P_{t-1}$ is the inflation rate, $\rho_{m} \in(0,1), \phi_{\pi}>1, \phi_{y} \geq 0$ and $\epsilon_{m, t}$ is an i.i.d. innovation. ${ }^{14}$

The presence of long-term bonds modifies the standard government budget constraint

$$
B_{t}+P_{L, t} B_{t}^{L}=R_{t-1, t} B_{t-1}+\left(1+\kappa P_{L, t}\right) B_{t-1}^{L}+P_{t} G_{t}-T_{t}
$$

The left-hand side of expression (2.10) is the market value, in nominal terms, of the total amount of bonds (short-term and long-term) issued by the government at time $t$. The righthand side is the total deficit at time $t$, that is, the cost of servicing bonds maturing in that period plus spending $G_{t}$ net of taxes.

We assume that the government controls the supply of long-term bonds following a simple autoregressive rule for their de-trended market value in real terms

$$
\frac{P_{L, t} B_{t}^{L}}{P_{t} Z_{t}}=\left(\frac{P_{L, t-1} B_{t-1}^{L}}{P_{t-1} Z_{t-1}}\right)^{\rho_{B}} e^{\epsilon_{B, t}},
$$

\footnotetext{
${ }^{14}$ The presence of output growth, instead of the output gap, in the interest rate rule avoids the complication of solving for and estimating the system of equations that characterise the flexible price equilibrium of the model. In practice, GDP growth relative to trend is often cited as one of the main indicators of real activity for the conduct of monetary policy.
} 


\section{The Macroeconomic Effects of LSAP Programs}

where $\rho_{B} \in(0,1)$ and $\epsilon_{B, t}$ is an i.i.d. exogenous shock. We interpret LSAP programs as shocks to the composition of outstanding government liabilities compared to the historical behaviour of these series.

Finally, the government adjusts the real primary fiscal surplus in response to the lagged real value of long-term debt, as in Davig and Leeper (2006) and Eusepi and Preston (2011),

$$
\frac{T_{t}}{P_{t} Z_{t}}-\frac{G_{t}}{Z_{t}}=\Phi\left(\frac{P_{L, t-1} B_{t-1}^{L}}{P_{t-1} Z_{t-1}}\right)^{\phi_{T}} e^{\epsilon_{T, t}}
$$

where $\phi_{T}>0$ and $\epsilon_{T, t}$ follows a stationary AR(1) process. All fiscal variables in rule (2.12) are cyclically adjusted (i.e. expressed relative to the level of productivity) and the constant $\Phi$ is such that in steady state the fiscal rule is just an identity. Note that the presence of asset market segmentation breaks Ricardian equivalence in this model. Therefore, fiscal financing

decisions have real consequences on the allocation. Given a strong enough feedback (a high enough value of the coefficient $\phi_{T}$ ), rule (2.12) ensures that the primary surplus adjusts to satisfy the government intertemporal budget constraint.

\subsection{Equilibrium and Solution Strategy}

In equilibrium, households and firms maximise their objectives subject to their constraints and all markets clear. In particular, the resource constraint is

$$
Y_{t}=\omega_{u} C_{t}^{u}+\omega_{r} C_{t}^{r}+I_{t}+G_{t}+a\left(u_{t}\right) \bar{K}_{t-1}
$$

We solve the model by taking a first-order log-linear approximation around a steady state in which quantities are normalised by the level of productivity $Z_{t}$ and relative prices are expressed as function of $P_{t}$. The technical appendix shows the full set of non-linear normalised equilibrium relations, characterises the steady state solution, and presents the 


\section{The Macroeconomic Effects of LSAP Programs}

full set of log-linearised equations that constitute the basis for the estimation.

These conditions are standard in modern DSGE models (Christiano et al., 2005; Smets and Wouters, 2007) with the exception of the households' consumption-saving decisions. Here, we focus on these Euler equations to sharpen the intuition about the effects of segmentation in the bond market. This discussion should also clarify the channels through which asset purchase programs can support macroeconomic outcomes.

Since only unrestricted households trade in short-term bonds, the pricing equation for these securities is

$$
1=\beta_{u} \mathbb{E}_{t}\left[e^{-\gamma-z_{t+1}} \frac{\Xi_{t+1}^{u}}{\Xi_{t}^{u}} \frac{R_{t}}{\Pi_{t+1}}\right]
$$

where $\Xi_{t}^{u}$ is the marginal utility of de-trended consumption in real terms for an unrestricted household and $e^{-\gamma-z_{t+1}}$ is the correction factor due to productivity growth.

Both unrestricted and restricted households trade long-term bonds. For unrestricted households, the pricing equation of these securities is

$$
\left(1+\zeta_{t}\right)=\beta_{u} \mathbb{E}_{t}\left[e^{-\gamma-z_{t+1}} \frac{\Xi_{t+1}^{u}}{\Xi_{t}^{u}} \frac{P_{L, t+1}}{P_{L, t}} \frac{R_{L, t+1}}{\prod_{t+1}}\right]
$$

For constrained households, the pricing condition is

$$
1=\beta_{r} \mathbb{E}_{t}\left[e^{-\gamma-z_{t+1}} \frac{\Xi_{t+1}^{r}}{\Xi_{t}^{r}} \frac{P_{L, t+1}}{P_{L, t}} \frac{R_{L, t+1}}{\Pi_{t+1}}\right] .
$$

Restricted households have a different marginal utility of consumption and do not pay the transaction cost.

\subsection{1 transaction costs and the risk premium}

The presence of transaction costs for unrestricted households in the market for long-

term bonds gives rise to a risk premium. Using equation (2.14), we define $R_{L, t}^{E H}$ as the 


\section{The Macroeconomic Effects of LSAP Programs}

counterfactual yield to maturity on a long-term bond at time $t$ in the absence of transaction costs, given the same path for the marginal utility of consumption of unrestricted households. No arbitrage implies that this fictitious bond should have the same risk-adjusted return as the long-term security actually traded. We measure the risk premium as the difference between these two yields to maturity, up to a first order approximation

$$
\hat{R}_{L, t}-\hat{R}_{L, t}^{E H}=\frac{1}{D_{L}} \sum_{s=0}^{\infty}\left(\frac{D_{L}-1}{D_{L}}\right)^{s} \mathbb{E}_{t} \zeta_{t+s},
$$

where $D_{L}$ is the steady state duration of the two securities. ${ }^{15}$ Expression (2.16) shows that the risk premium in this economy equals the present discounted value of current and expected future transaction costs.

In ALSN, the risk premium has two components, one endogenous and one exogenous. The endogenous component arises because households face a portfolio adjustment cost, function of the relative quantity of money relative to long-term assets. The idea is that long-term bonds entail a loss of liquidity that households hedge by increasing the amount of money in their portfolio. The transaction costs in the market for long-term bonds are treated as purely exogenous.

We retain the distinction between endogenous and exogenous component of the risk premium while abstracting from the portfolio adjustment cost component. Instead, we directly assume that transaction costs are function of the ratio of market value of long-term debt to short-term debt in the hands of the public, plus an error

$$
\zeta_{t} \equiv \zeta\left(\frac{P_{L, t} B_{z, t}^{L}}{B_{z, t}}, \epsilon_{\zeta, t}\right)
$$

\footnotetext{
${ }^{15}$ The details of the derivation are in the technical appendix. In defining the yield to maturity of a bond in the absence of transaction costs, we adjust the parameter $\kappa$ to guarantee that the fictitious security has the same steady state duration as the actual long-term bond.
} 


\section{The Macroeconomic Effects of LSAP Programs}

where $B_{z, t}^{L} \equiv B_{t}^{L} /\left(P_{t} Z_{t}\right)$, and $B_{z, t} \equiv B_{t} /\left(P_{t} Z_{t}\right)$. We do not take a stand on the explicit functional form of $\zeta($.$) . We only require the function and its first derivative to be positive$ when evaluated in steady state (i.e. $\zeta\left(P_{L} B_{z}^{L} / B_{z}, 0\right)>0$ and $\left.\zeta^{\prime}\left(P_{L} B_{z}^{L} / B_{z}, 0\right)>0\right)$. The first assumption ensures the presence of a positive steady state risk premium, as in the data. The second assumption guarantees that the yield on long-term bonds drops following a reduction in their outstanding amount. This element gives LSAP programs a chance to work through the mechanism identified in the reduced form estimates (Gagnon et al., 2011).

Up to a log-linear approximation, our parsimonious formulation of transaction costs is observationally equivalent to the two frictions in ALSN. The idea that transaction costs depend directly on the aggregate stock of bonds captures the same intuition (i.e. a liquidity cost) of the adjustment cost function in the original formulation. ${ }^{16}$

\subsection{2 limits to arbitrage}

The assumption of market segmentation captures, in reduced form, the observation that in reality some fraction of the population mostly saves through pension funds and other types of long-term institutional investors. These financial intermediaries are specialists in certain segments of the market and their transaction costs are likely to be small. Conversely, households who invest in long-term bonds mostly for diversification motives may face higher transaction costs. ${ }^{17}$ The parameter $\omega_{u}$ measures this segmentation and is one of the key objects of interest in our estimation results.

The key implication of bond market segmentation is that not all agents in the model can take full advantage of arbitrage opportunities. Unrestricted households can arbitrage away, up to some transaction cost, differences in risk-adjusted expected returns between short

\footnotetext{
${ }^{16}$ An alternative approach to study the effects of LSAP programs on risk and term premia would be to use higher order approximation methods and estimate the model with the particle filter (van Binsbergen et al., 2010).

${ }^{17}$ See ALSN for a more detailed discussion of this interpretation.
} 


\section{The Macroeconomic EfFects of LSAP Programs}

and long-term bonds (equations 2.13 and 2.14) but restricted households do not have this possibility. Equation (2.15) fully characterises the savings behaviour of restricted households.

This friction provides a rationale for asset purchase programs to influence macroeconomic outcomes, thus breaking the irrelevance result in Wallace (1983). In particular, in our model, a program targeted to purchases of long-term securities reduces the risk premium (equation 2.17), changing their expected return. Absent segmentation, this program would affect the yield to maturity of the long-term bond (equation 2.14) but would have no effects on the real allocation. Because unrestricted households can invest in both securities, their portfolios would adjust until the two expected returns are equated again, implying a different yield to maturity on the long-term bond. In equilibrium, expected returns, inclusive of transaction costs, would be unchanged, hence avoiding any change of the stochastic discount factor. Thus, no real variable in this economy is affected.

Conversely, with segmented bond markets, LSAP programs do affect the real economy. The change in long-term yields induces a change in the expected return of the restricted households, which are not subject to the transaction costs. Because the expected return is different from the restricted households' perspective, their stochastic discount factor has to adjust. This change alters their intertemporal profile of consumption (equation 2.15) and indirectly influences both the pricing decisions of intermediate producing firms and the investment decisions of capital producers. Ultimately, general equilibrium forces imply that consumption for both types of agents, investment and production respond as well. ${ }^{18}$ The simulations in section 4 illustrate the magnitude of the LSAP stimulus on aggregate demand and inflation.

\footnotetext{
${ }^{18}$ In practice, another effect of asset purchase programs could be the incentive for households to shift their portfolios toward riskier assets, such as equity and corporate bonds. In the model, this mechanism is absent as the equity shares are non-tradable.
} 


\section{The Macroeconomic Effects of LSAP Programs}

\section{Empirical Analysis}

We estimate the model with Bayesian methods, as surveyed for example by An and Schorfheide (2007). Bayesian estimation combines prior information on the parameters with the likelihood function of the model to form the posterior distribution. We construct the likelihood using the Kalman filter based on the state space representation of the rational expectations solution of the model. ${ }^{19}$ In the remainder of this section, we first describe the data used and then present parameter prior and posterior distributions.

\subsection{Data}

We use quarterly data for the United States from the third quarter of 1987 (1987q3) to the third quarter of 2009 (2009q3) for the following seven series: real GDP per capita, hours worked, real wages, core personal consumption expenditures deflator, nominal effective Federal Funds rate, the 10-year Treasury constant maturity yield, and the ratio between long-term and short-term U.S. Treasury debt. ${ }^{20}$ All data are extracted from the Federal Reserve Economic Data (FRED) maintained by the Federal Reserve Bank of St. Louis. in the technical appendix we describe more precisely how the data is constructed and how it maps to the state variables in the model.

\subsection{Prior Choice}

Tables 2 and 3 (columns two to five) summarise the prior distributions of each parameter. We use a Gamma distribution for the parameters that economic theory suggests should be positive to constrain their support on the interval $[0, \infty]$. For those parameters that span

\footnotetext{
${ }^{19} \mathrm{We}$ impose a zero posterior density for parameter values that imply indeterminacy, which is equivalent to a truncation of the joint prior distribution.

${ }^{20}$ We use an extended sample, starting in 1959q3, to initialise the Kalman filter, but the likelihood function itself is evaluated only for the period starting in 1987q3, conditional on the previous sample.
} 


\section{The Macroeconomic Effects of LSAP Programs}

only the unit interval, we use the Beta distribution. For the standard deviation of shock innovations, we use the Inverse-Gamma distribution.

The steady state value for inflation is centred at $2 \%$, in line with the mandate-consistent level of inflation commonly assigned to the Federal Open Market Committee (FOMC). The steady state growth rate is centred at $2.5 \%$ (annualised). The discount factor has a prior that implies a real interest rate of about $2 \%$ (annualised). The steady state spread between the 10-year treasury yield and the federal funds rate has a prior centred at $0.75 \%$ (annualised), similar to the average in the data.

We follow Del Negro and Schorfheide (2008) for the priors of standard parameters. The investment adjustment cost convexity parameter $S^{\prime \prime}$ has prior mean of 4 and standard deviation of 1 . The utilisation cost elasticity parameter $a^{\prime \prime}$ has prior mean 0.2 and standard deviation 0.1 , implying that in response to a $1 \%$ increase in the return to capital, utilisation rates rise by about $0.17 \%$. We calibrate the share of capital in production $\alpha$ to 0.33 , and the capital depreciation rate $\delta$ to $2.5 \%$ per quarter.

The habit formation coefficient for both types of agents has prior mean of 0.6 and standard deviation 0.1 , also fairly common in the literature. The parameter controlling the labour supply elasticity $\nu$ has a prior centred at 2. Similarly to Smets and Wouters (2007), we estimate the intertemporal elasticity of substitution of consumption for households, except that in our model we have two types of agents. The prior on $\sigma_{u}$ and $\sigma_{r}$ is relatively flat (centred at 2 with standard deviation of 1) and equal for both types, so that the data can be informative about their value.

The fraction of unrestricted agents $\omega_{u}$ is the crucial parameter to identify the degree of bond market segmentation in the model. At the mean, our prior implies that $70 \%$ of the households are unrestricted. As we show below, this degree of segmentation, conditional on the rest of the priors, is consistent with substantial effects of LSAP in the model. A standard deviation of 0.2 , however, makes the distribution flat enough that the $90 \%$ prior interval is 


\section{The Macroeconomic Effects of LSAP Programs}

$(0.32,0.96)$ and encompasses very large to minimal effects. The other key parameter is the elasticity of the risk premium to changes in the market value of long debt $\zeta^{\prime}$. The prior for this parameter has a mean 1.5/100 and a standard deviation big enough to match the range of estimates shown in Table 1 (see discussion above). The cash-flow parameter that controls the duration of long-term bonds (given the yield to maturity) is calibrated to imply a duration of 30 quarters, similar to the average duration in the secondary market for 10-year U.S. Treasury bills. We consider short-term debt to include both government bonds with less than one year to maturity as well as central bank liabilities in the form of reserves, vault cash and deposits. In the U.S., the average for this quantity since 1974 is about $16 \%$ of annual GDP. For long-term bonds, we consider all government bonds with maturity greater than one year, which in the U.S. is also about 16\% of annual GDP since 1974.

Table 2 contains three non-standard parameters $\left(\Xi^{u} / \Xi^{r}, C^{u} / C^{r}\right.$, and $\left.\chi_{w u}\right)$ which refer to steady state ratios hard to pin down directly from the data. We decided not to calibrate these ratios to avoid biasing the estimation and the simulations in either direction. The posterior distribution for these three parameters turns out to deviate negligibly from our prior. Furthermore, the uncertainty in these ratios translates into uncertainty in the dynamics of the model and in the effects of asset purchases on macroeconomic variables.

The priors for the wage and price rigidity parameters $\zeta_{w}$ and $\zeta_{p}$ are centred at 0.5 with a standard deviation of 0.1 , as in Smets and Wouters (2007). The fiscal rule parameter, $\phi_{T}$ is centred at 1.5 and its posterior does not differ too much from the prior. For the monetary policy rule, we consider fairly standard parameter priors. The interest rate smoothing parameter $\rho_{r}$ is centred at 0.7 . The response to output growth $\phi_{y}$ is centred at 0.4 . The prior mean for the response to inflation $\phi_{\pi}$, centred at 1.75 , is slightly higher than the usual value of 1.5 in Taylor (1993). The 90\% prior interval, however, is completely above one, consistent with the Taylor principle.

The shocks follow $\mathrm{AR}(1)$ processes, with autocorrelation coefficient $\rho_{i}$ centred at 0.75 , 


\section{The Macroeconomic EfFects of LSAP Programs}

except for the autocorrelations of productivity shocks (equal to 0.4 so that the growth rate shock is not too persistent) and of the risk premium and debt shocks (equal to 0.8). The prior mean of the innovations have standard deviations $\sigma_{i}$ centred at 0.5 , except for the innovation to the monetary policy shock and the risk premium shock whose standard deviation is smaller because these variables refer to quarterly changes in interest rates.

\subsection{Parameter Posterior Distribution}

In order to obtain the posterior distribution, we first obtain the posterior mode. ${ }^{21} \mathrm{We}$ then use a normal approximation around the mode to form a jump distribution to generate a sample of parameter vector draws representative of the posterior based on the Metropolis random walk Markov Chain Monte Carlo (MCMC) simulation method. ${ }^{22}$ The last five columns of tables 2 and 3 report the posterior distribution of each parameter.

The first result that emerges from these tables is that the measure of market segmentation is very small - the posterior $90 \%$ interval for $\omega_{u}$ is $(0.824,0.993)$ with a median of 0.947 and a mode of 0.983 . Given our prior, the data strongly pushes against a model with a significant degree of market segmentation. Ceteris paribus, we should expect small macroeconomic effects of asset purchases. In order to check the stability of the estimate of market segmentation (and, in general, of other parameters), we re-estimated the model with alternative samples. While in our baseline estimation the sample ends in 2009q3 (just before the first U.S. LSAP program), we considered three alternative endings: 2007q2 (before the recent financial turbulence), 2008q3 (before the federal funds rate reached the ZLB)

\footnotetext{
${ }^{21}$ We extract the mode by maximising the posterior density function, which can be a very challenging task with a high-dimensional problem like the one in this paper. In order to reduce the chances of extracting a local maximum, we perform 50 maximizations of the mode starting at different guesses of the parameter vector. For each solution, we further test at least ten times whether a new maximisation with a guess parameter vector in a small neighbourhood of that solution can achieve a higher level of the posterior density function.

${ }^{22}$ After obtaining four separate chains of 100,000 draws, we compute the covariance matrix (with a $25 \%$ burn-in) and generate four new chains of 100,000 draws. We repeat this step two more times with 200,000 and 500,000 draws, respectively. At this stage, we use these last four chains to extract the parameter posterior distribution properties and to simulate the effects of asset purchases.
} 


\section{The Macroeconomic Effects of LSAP Programs}

and 2011q2 (the most recent available data). The parameter estimates always remain very comparable. $^{23}$

The other key parameter is the elasticity of the risk premium to asset purchases $\zeta^{\prime}$. If this elasticity were zero, asset purchases would affect neither the risk premium nor the real economy. The posterior distribution turns out to be concentrated at low levels, although different from zero, with a median of $0.327 / 100$ and a $90 \%$ interval of $(0.086,0.826)$, suggesting a fairly small impact of the quantity of debt on the risk premium and the 10 -year yield. This finding collocates our estimate of the elasticity of the risk premium to the quantity of debt at the lower end of the spectrum in the literature.

The sensitivity of consumption to the interest rate is estimated to be 3.4 for the unrestricted type and 2.1 for the restricted type at the posterior median. These numbers suggest a specification of utility far enough from the usual log-utility assumption but also significant heterogeneity in the sensitivity to the interest rate for the two types. Finally, the posterior moments for the nominal rigidity parameters and policy rule coefficients are consistent with several contributions in the DSGE literature (e.g. Del Negro and Schorfheide, 2008). Importantly, price rigidities are estimated to be quite high relative to the micro-evidence. These parameters may significantly influence the simulations. Therefore, in the robustness analysis, we repeat our baseline experiment with $\zeta_{p}$ set at the prior mean.

\subsection{Interest Rate Diagnostics}

This section briefly discusses a number of interest rate diagnostics (variance, variance decomposition, historical shock decomposition). More details, including tables and plots, are available in the appendix.

As we use data on both short and long-term interest rates, our model can match the

\footnotetext{
${ }^{23}$ One caveat is that most of our sample corresponds to a period of relative macroeconomic and financial stability in the U.S.. Because the recent crisis may have exacerbated financial frictions, we subject our main experiment to a robustness check where we allow for an (exogenous) increase in the degree of segmentation.
} 


\section{The Macroeconomic EfFects of LSAP Programs}

exact path of these variables through Kalman filtering and smoothing. Nonetheless, we can also compute the model-based unconditional moments for each variable. In particular, we focus on the variance of interest rates that the model is able to produce given the posterior distributions of the parameters. ${ }^{24}$ Our DSGE model captures more than half of the variance of the FFR in the data (0.44 versus 0.81$)$ and about one quarter of the ten-year yield $(0.12$ versus 0.47). ${ }^{25}$ While our DSGE model, like most, fails to completely explain the term structure, we nevertheless provide a theory of how changes in long-term rates affect the real economy.

Different shocks explain the variance of short and long-term interest rates. For the FFR, the shock to the marginal efficiency of investment is the single most important driver of the variance at business cycle frequencies (periodic components with cycles between 6 and 32 quarters), consistent with the findings in Justiniano et al. (2010). In the shorter run, shocks to the monetary policy rule play a non-trivial role while at longer horizons preference shocks become relevant. The volatility of long-term rates is mostly accounted for (roughly 60\%) by shocks to the risk premium, with preference and marginal utility of investment shocks splitting the remaining $40 \%$ of the variance more or less equally.

The historical shock decomposition is related to the variance decomposition but is conditional on the actual path of the data. The product of the historical shock decomposition is the marginal contribution of each shock to the path of each variable in the model. As with the variance, we report results for the median across 1000 draws. Shocks to the risk premium pushed down the FFR since 1994, between 2 and 3 percentage points. Since 2007, monetary policy shocks have been exerting the opposite pressure. Our model hence suggests

\footnotetext{
${ }^{24}$ To compute the model-based unconditional variance of a certain variable, we draw a vector of parameters from the joint posterior distribution, compute the unconditional variance of the variable of interest, repeat the procedure 1000 times and then take the median.

${ }^{25}$ The performance for long-term rates is not much worse than three-factors affine models of the term structure of interest rates. For example, the $R^{2}$ of the regression for the ten-year yield in Balduzzi et al. (1996) is $31 \%$.
} 


\section{The Macroeconomic EfFects of LSAP Programs}

that economic conditions, not discretionary policy decisions, account for the low policy rate during the recent financial crisis. ${ }^{26}$ The shock to the marginal efficiency of investment - the key factor in the variance decomposition - captures fairly well the cyclical movements in the FFR with two notable exceptions: the early 1990s, when $\mu_{t}$ exercises downward pressures while the FFR is actually going up, and the end of the sample, when $\mu_{t}$ shock is pushing the FFR up. The same risk premium shocks that put downward pressure on the FFR since 1994 exert the opposite force on long-term rates, although other shocks (in particular, preference and productivity) partly offset this dynamics, especially at the end of the sample.

\section{Simulating LSAP II}

Our baseline experiment corresponds to a simulation of the U.S. LSAP II program, announced with the FOMC statement of November 3, 2010. The central bank buys long-term bonds (in exchange for short-term bonds) over the course of four quarters, holds its balance sheet constant for the following two years and progressively shrinks its holdings of long-term securities over the final two years of the simulation. We calibrate the size of the asset purchase program to match a $\$ 600$ billion reduction of long-term debt in the hands of the private sector. Figure 1 illustrates the path of the market value of long-term bonds in the hands of the private sector (in deviations from trend) following the central bank purchases. ${ }^{27}$

We also impose that the FFR stays at the ZLB for the first four quarters after the beginning of the asset purchase program (the "extended period" language), consistent with the survey evidence from Blue Chip. ${ }^{28}$ In the technical appendix, we explain the exact details

\footnotetext{
${ }^{26}$ Because the FFR eventually hit the zero lower bound in the Fall of 2008, one way to recast this result is that the interest rate rule in the model calls for negative nominal interest rates.

${ }^{27}$ To be precise, we perform the simulation by feeding a series of shocks to the rule controlling the level of long-term bonds in the hands of the public that is announced to all agents in the economy. As such, the private sector is aware of the whole path when forming expectations about the future.

${ }^{28}$ Blue Chip has been asking the survey participants about the expected duration of the ZLB since the end of 2008. Until the recent (FOMC statement of August 9, 2011) change in the Federal Open Market
} 


\section{The Macroeconomic Effects of LSAP Programs}

of how we implement this commitment to the zero lower bound.

We begin by showing our main simulation of LSAP II at the prior distribution and then repeat the same experiment at the posterior. The following two subsections discuss the role of the commitment to the zero lower bound and how LSAP compares to interest rate policy shocks. In the technical appendix we present several robustness results.

\subsection{Simulation at the Prior Distribution}

This section illustrates how the choice of the priors constrains the macroeconomic effects of asset purchase programs via Monte Carlo simulations. Specifically, we obtain 1000 random draws for the parameter vector using the prior distribution. We then use each of these draws to solve the model and extract the path of the state variables in response to the LSAP experiment described above. Finally, we compute moments and percentiles of this sample of responses for the variables of interest. ${ }^{29}$

Figure 2 shows the response of output growth, output level, inflation, FFR, 10-year yield and risk premium to the simulated LSAP II experiment at the prior distribution, all in annualised percentage rates. The level of output corresponds to percentage deviations from trend, as opposed to a rate of change, and thus is not annualised. These plots represent the marginal contribution of LSAP II, i.e. the deviations of each variable relative to the path that would have prevailed absent the policy intervention. The red continuous line is the prior median response while the grey shaded area corresponds to the $50^{t h}, 60^{t h}$, $70^{t h}$, and $80^{\text {th }}$ prior probability intervals, from darker to lighter shading respectively.

The prior for the elasticity of the risk premium to the quantity of long-term debt implies a median response at the peak of about $30 \mathrm{bp}$, consistent with the estimates in Gagnon

Committee language that introduced a specific date for the expected liftoff, market participants had always maintained the expectation that the FFR would remain at the ZLB for the four/five quarters after the question was asked.

${ }^{29}$ The results are not sensitive to increasing the number of draws. 


\section{The Macroeconomic Effects of LSAP Programs}

et al. (2011). The uncertainty bands cover pretty much the whole range of estimates in the empirical literature discussed in the introduction and summarised in Table 1. As a consequence of the change in the risk premium, output growth, the output level and inflation are higher than in the absence of asset purchases. By construction, the asset purchase program achieves the desired effect in the model. The key question is how big these effects are. Our prior is fairly generous, encompassing very large effects, but also relative agnostic, as to extract as much information as possible from the data without imposing too many exante restrictions. To be more precise, the median prior response of output growth is $2.7 \%$ and the median response of inflation is $1.08 \%$, roughly in line with the results in Baumeister and Benati (2011). Using a vector auto regression (VAR) model with time-varying coefficients, these authors find that a $60 \mathrm{bp}$ reduction in long-term rates increases GDP growth by $3 \%$ and the inflation rate of the GDP deflator by $1 \%$ at the posterior median.

Our prior may be seen as too generous to the extent that we allow the effects of LSAP to be potentially quite extreme (for example the $80^{t h}$ percentile is above $15 \%$ for GDP growth and inflation). The literature, however, does not rule out these extreme outcomes. For example, Kapetanios et al. (2011) present VAR evidence for the effects of similar policies on GDP growth in the United Kingdom that can be as high as 5\% at the mean, depending on the estimation method. Our choice of fairly uninformative priors gives the model a chance to generate such large effects.

In response to higher output and inflation, the central bank eventually increases the interest rate in accordance with the policy rule, but only after the end of the commitment to the ZLB. The evolution of the 10-year yield reflects the combined effect of the responses of the risk premium and the expected future short-term interest rate (expectations hypothesis). The former puts negative pressure on the long yield while the latter exerts the opposite pressure. The outcome depends on how effective asset purchases ultimately are in boosting the economy. If LSAP programs have a significant effect on output and inflation, the policy 


\section{The Macroeconomic Effects of LSAP Programs}

rule dictates a strong response of the federal funds rate which can potentially dominate over the negative impact on the risk premium and lead to an equilibrium increase in the 10-year yield.

\subsection{Simulation at the Posterior Distribution}

In the previous subsection, we concluded that, according to this model and our choice of the priors for the parameters, LSAP programs can boost output and inflation while the effect on the 10-year yield is somewhat ambiguous, depending on the interplay between the risk premium and the expectation hypothesis. In this section, we combine the prior with the data for the past twenty years or so to form a posterior distribution of the parameters. We then use the posterior to revisit our simulations of the effects of LSAP II. Figure 3 shows the same variables and simulation as Figure 2, but now using parameter draws from the posterior distribution.

The policy intervention reduces the risk premium by $11 \mathrm{bp}$ on impact at the posterior median, reflecting the small elasticity of this variable to the quantity of debt discussed earlier. Combined with a small estimated degree of segmentation, not surprisingly the effects of LSAP II on aggregate activity are modest. On impact, GDP growth increases by $0.13 \%$ at the posterior median. The uncertainty is skewed on the upside to about $0.6 \%$, partly due to the ZLB. After three quarters, the effect on output growth is less than a half of its peak (which occurs on impact) and completely vanishes after eight quarters. The effects on the level of output are modest too. The peak in this case occurs after 6 quarters at about 0.1\% (posterior median), but now the effects persist longer-after 24 quarters, the output level is still more than $0.05 \%$ higher than without asset purchases. The reason for the high level of persistence of the level of real economic activity is that the asset purchase program induces small but long-lasting movements in real interest rates. ${ }^{30}$ This modest but persistent

\footnotetext{
${ }^{30}$ The persistence of both inflation and the nominal interest rate after exiting the ZLB is quite evident
} 


\section{The Macroeconomic Effects of LSAP Programs}

effect on GDP level is likely to be important from a welfare perspective- even more so if we consider that the $90^{\text {th }}$ probability interval allows for an increase in the level of GDP as high as $0.5 \%$. The effect on inflation is very small, 3 annualised bp at the median, and skewed upward, but even the $95^{\text {th }}$ percentile is only about $15 \mathrm{bp}$.

In spite of the small magnitudes, the positive boost of asset purchases to GDP growth and inflation puts upward pressure on the interest rate. After the four quarters at the ZLB which correspond to the commitment period, the FFR becomes positive but the median increase is only $4 \mathrm{bp}$. Because asset purchases introduce little stimulus, the central bank does not raise interest rates by much upon exiting the ZLB. The upward skewness in the FFR reflects the skewness in the effects on GDP growth and inflation. Later, we disentangle the effects of the non-linearity introduced by the ZLB from the pure estimation uncertainty.

The drop in the 10-year yield almost coincides with the reduction in the risk premium. Because the FFR only increases few basis points upon exiting the ZLB, the expectation hypothesis component of long-term rates plays a minor role.

Importantly, the duration of the ZLB commitment interacts with the LSAP program. Recently, the Federal Reserve has extended its commitment to keep the nominal interest rate at zero for a longer period. ${ }^{31}$ The marginal effect of increasing the ZLB commitment by one extra quarter almost doubles the effects on GDP growth and GDP level while the effect on inflation is $50 \%$ bigger. ${ }^{32}$ These results show very clearly that in this model the ZLB commitment is very powerful in stimulating the economy, due to the strongly forward looking behaviour of the agents in the economy, and its effects increase non-linearly with the number of quarters of the commitment.

To summarise, the effects of LSAP II on GDP and inflation are modest, especially compared to the simulation at the prior, although the effects on the output level are quite

from Figure 3.

${ }^{31}$ At the time we are writing this paper, the commitment is "at least through late 2014."

${ }^{32}$ More details are available in the appendix. 


\section{The Macroeconomic Effects of LSAP Programs}

persistent. The main reason for this result is that the two crucial parameters that control the effects of asset purchases on real activity - the degree of segmentation and the elasticity of the risk premium to the quantity of debt in the hands of the private sector - are estimated to be small. Yet, the posterior distributions for both these parameters are skewed so that we cannot completely discard the possibility of larger effects. Together with the ZLB, the long tails of the posterior estimates for $\omega_{u}$ and $\zeta^{\prime}$ contribute to the upward skewness of the response of GDP growth and inflation in the baseline simulation.

Our results are at the lower end of the spectrum in the existing literature. Beside the estimates in Baumeister and Benati (2011) mentioned earlier, Chung et al. (2011), using the FRB/US model, assume that LSAP II induces a reduction in the risk premium of only 20 bp but increases the level of GDP by about $0.6 \%$ and inflation rate by $0.1 \%$.

The results in this section are subject to the caveat, discussed for example in D'Amico et al. (2011), that the use of aggregate data on debt may bias the results, weakening the effects of asset purchases on yields. One possible rationalisation of this bias is that our treatment of the sample as homogeneous may have overlooked a structural change in the underlying structure of financial markets caused by the recent crisis. Alternatively, active debt management policy by the Treasury, in an attempt to minimise the financing costs of debt issuance, may make the elasticity of the risk premium to the quantity of debt hard to estimate. Under this hypothesis, the Treasury internalizes the asset market friction to minimise the interest rate cost of marginal funding so that, ex-post, the data display very little relationship between yield spreads and relative supply of assets at different maturities. ${ }^{33}$

In the working paper version of this study (Chen et al., 2011), we estimate the model without using observations on the quantity of debt. In that case, our prior on the elasticity of the risk premium to the quantity of debt encompasses most of the estimates in the empirical literature. Because the elasticity is not well-identified in this case, the posterior median

\footnotetext{
${ }^{33}$ We thank the referee for suggesting this interpretation.
} 


\section{The Macroeconomic Effects of LSAP Programs}

coincides with the prior, which corresponds to a cumulative effect of $-30 \mathrm{bp}$ on the risk premium in response to LSAP II (e.g. Gagnon et al., 2011). Under this specification, LSAP II increases GDP growth by $0.4 \%$ at the posterior median, while the impact on inflation is very similar to the case in which the quantity of debt is used in the estimation. ${ }^{34}$

\subsection{The Role of the ZLB}

In this subsection, we show that the commitment of the central bank to keep the shortterm nominal interest rate at the ZLB for an "extended period" amplifies the effects of LSAP II. According to our simulations, asset purchases boost GDP growth and increase inflation, thus leading the central bank to increase the FFR. This endogenous interest rate response mitigates the macroeconomic stimulus of asset purchase programs through the conventional monetary policy channel. A commitment to keep the short-term nominal interest rate at the ZLB for an "extended" period of time prevents the endogenous response of the monetary authority and magnifies the contribution of asset purchases on macroeconomic outcomes. Here, we quantify the magnitude of such a mitigation effect.

Figure 4 shows the responses in the case in which we do not impose the commitment to the zero lower bound. For reference, the dashed blue line corresponds to the baseline simulation with the commitment to the ZLB imposed. Quantitatively, the ZLB commitment more than triples the effects of asset purchases on GDP growth. Absent this commitment, output growth increases by $0.04 \%$, compared to $0.13 \%$ in the baseline experiment. Inflation increases by less than $2 \mathrm{bp}(0.018 \%)$, compared to $3 \mathrm{bp}$ in the baseline case.

Interestingly, while the profile for the FFR differs from the baseline, the 10-year yield is almost identical. The cumulative effect of the increase in short rates on long rates via the expectation-hypothesis component is the same. Without ZLB, the increase in nominal rates

\footnotetext{
${ }^{34}$ Interestingly, the estimated degree of segmentation does not change appreciably between the two cases. Hence, the different effect on GDP growth is to attribute entirely to the elasticity of the risk premium to the quantity of debt.
} 


\section{The Macroeconomic Effects of LSAP Programs}

occurs earlier but is smoother.

Importantly, the responses to LSAP II remain skewed upward, regardless of whether the ZLB is imposed or not. This observation suggests that the role of the skewness in the posterior distribution of the degree of segmentation and of the semi-elasticity of the risk premium to the quantity of debt play a central role in explaining the upside uncertainty of the response of macroeconomic variables.

\subsection{Comparison with a Standard Monetary Policy Shock}

One of the motivations for central banks to engage in asset purchases is to support output and inflation at times in which the ZLB constrains conventional interest rate setting. To give a sense of the relative effectiveness of these two policies, this section compares the effects of asset purchase programs discussed so far with a standard monetary policy shock, that is, an unexpected reduction of the short-term nominal interest rate.

Figure 5 shows the response of the key macroeconomic variables to an unexpected reduction of $25 \mathrm{bp}$ in the short-term interest rate. The median effect on GDP growth is somewhat stronger than in the baseline simulation previously discussed while the median effect on inflation is very much comparable. ${ }^{35}$ Furthermore, the effects of the interest rate shock on the output level are not only stronger but also more persistent than those of LSAP. The implied decrease in long-term rates, however, is much smaller, only $1 \mathrm{bp} .{ }^{36}$ Moreover, the long-term rate quickly turns positive. This result is not surprising given that the risk premium does not change. Therefore, the expectation hypothesis component completely pins down the long-term interest rate in this case.

\footnotetext{
${ }^{35}$ The median effects of the monetary policy shock on output and inflation in our model are slightly smaller than in standard estimated DSGE models, such as Smets and Wouters (2007). The key parameters that determine this result are the higher estimated degree of price rigidity and the lower sensitivity of demand to the interest rate (higher coefficient of risk aversion).

${ }^{36}$ Our estimates thus imply a much smaller sensitivity of long-term rates to shocks to the short-term rate. As a point of comparison, Gurkaynak et al. (2005) estimate that the typical response of long rates to a cut of $100 \mathrm{bp}$ in the FFR is $15 \mathrm{bp}$.
} 


\section{The Macroeconomic Effects of LSAP Programs}

Another significant difference is the smaller uncertainty about the effects in the case of an interest rate shock. The absence of the ZLB constraint may in part explain why the posterior bands are more symmetric. Yet, as discussed in the previous subsection, even in the absence of a commitment to the ZLB, uncertainty remains skewed upward, mostly due to the skewness of the posterior estimates of the degree segmentation and of the semi-elasticity of the term premium to the quantity of debt. Because asset market frictions play a smaller role in case of a shock to the short-term interest rate, the uncertainty in the response of GDP growth and inflation becomes smaller and much more symmetric.

Overall, in this model, the effects of LSAP II on output and inflation are slightly smaller than those of a surprise reduction of the FFR by $25 \mathrm{bp}$, and much more uncertain. This conclusion stands in contrast with Furher and Moore (1995), who find that output is four times more sensitive to long-term than short-term rates. According to this metric, the 11 bp reduction in the risk premium triggered by LSAP II should be equivalent to a reduction of the FFR of about $44 \mathrm{bp}$. Our results are thus much less generous to changes in the risk premium, confirming our previous finding that the model simulations yield weaker effects of LSAP II on output and inflation than what the VAR literature suggests.

\section{Conclusions}

Using an estimated medium-scale DSGE model, we find that the effects of recent asset purchase programs on macroeconomic variables, such as GDP growth and inflation, are likely to be modest, although with a lasting impact on the level of GDP. Asset purchase programs are in principle effective at stimulating the economy because of limits to arbitrage and market segmentation between short-term and long-term government bonds. The data, however, provide little support for these frictions to be pervasive.

In the appendix, we consider several robustness exercises and find that the effects on 


\section{The Macroeconomic Effects of LSAP Programs}

GDP growth are not very likely to exceed a third of a percentage point. The inflationary consequences of asset purchase programs are consistently small. Combining LSAP programs with a commitment to keep interest rates low for some period of time allows these programs to be more effective in boosting GDP growth and inflation.

Our results do not depend on whether asset purchases are financed via reserves or sales of short-term debt, to the extent that money and short-term bonds are close to perfect substitutes. Therefore, according to our model, the effects of the Federal Reserve's last round of asset purchases (also known as "Operation Twist Again") should be in line with the estimates from LSAP II after controlling for the scale factor.

\section{References}

An, S. and Schorfheide, F. (2007a.) 'Bayesian analysis of DSGE models', Econometric Reviews, vol. 26(2-4), pp. 113-72.

Andrés, J., López-Salido, J. and Nelson, E. (2004). 'Tobin's imperfect asset substitution in optimizing general equilibrium', Journal of Money, Credit and Banking, vol. 36(4), pp. $665-90$.

Balduzzi, P., Das, S., Foresi, S. and Sundaram, R. (1996). 'A simple approach to threefactors affine term structure models', Journal of Fixed Income, vol. 6, pp. 43-53.

Baumeister, C. and Benati, L. (2010). 'Unconventional monetary policy and the Great Recession', ECB Working Paper 1258.

van Binsbergen, J., Fernandez-Villaverde, J., Koijen, R. and Rubio-Ramirez, J. (2010). 'The term structure of interest rates in a DSGE model with recursive preferences', NBER Working Paper 15890.

Bomfim, A.N. and Meyer, L.H. (2010). 'Quantifying the effects of Fed asset purchases on Treasury yields', Monetary Policy Insights: Fixed Income Focus. 


\section{The Macroeconomic Effects of LSAP Programs}

Chen, H., Cúrdia, V. and Ferrero, A. (2011). 'The macroeconomic effects of large-scale asset purchase program', Federal Reserve Bank of New York Staff Reports 527.

Christiano, L., Eichenbaum, M. and Evans, C. (2005). 'Nominal rigidities and the dynamic effects of a shock to monetary policy', Journal of Political Economy, vol. 113(1), pp. $1-45$.

Chung, H., Laforte, J., Reifschneider, D. and Williams, J. (2011). 'Have we underestimated the likelihood and severity of zero lower bound events?', Working Paper, Board of Governors of the Federal Reserve System.

Cúrdia, V. and Woodford, M. (2010). 'Credit spreads and monetary policy', Journal of Money, Credit and Banking, vol. 42(s1), pp. 3-35.

Cúrdia, V. and Woodford, M. (2011). 'The central-bank balance sheet as an instrument of monetary policy', Journal of Monetary Economics, vol. 58, pp. 54-79.

D’Amico, S., English, W. ,López-Salido, D. and Nelson, E. (2011). 'The Federal Reserve’s large-scale asset purchase programs: Rationale and effects', Working Paper, Board of Governors of the Federal Reserve System.

D'Amico, S. and King,T. (2010). 'Flow and stock effects of large-scale Treasury purchases', Finance and Economics Discussion Series 2010-52, Board of Governors of the Federal Reserve System.

Davig, T. and Leeper, E. (2006). 'Fluctuating Macro Policies and the Fiscal Theory', in (D. Acemoglu, K. Rogoff, and M. Woodford, eds.) NBER Macroeconomics Annual, pp. 247-98, Cambridge: MIT Press.

Del Negro, M. and Schorfheide, F. (2008). 'Forming priors for DSGE models (and how it affects the assessment of nominal rigidities)', Journal of Monetary Economics, vol. 55, pp. 1191-1208.

Doh, T. (2010). 'The efficacy of large-scale asset purchases at the zero lower bound', FRB Kansas City Economic Review, Q2, pp. 5-34.

Eggertsson, G. and Woodford, M. (2003). 'The zero bound on interest rates and optimal monetary olicy', Brookings Papers on Economic Activity, vol. 1, pp. 139-211. 


\section{The Macroeconomic Effects of LSAP Programs}

Eusepi, S. and Preston, B. (2011). 'The maturity structure of debt, monetary policy and expectations stabilization', Working Paper, Federal Reserve Bank of New York.

Furher, J. and Moore, G. (1995). 'Monetary policy trade-offs and the correlation between nominal interest rates and real output', American Economic Review, vol. 85, pp. 219-39.

Gagnon, J., Raskin, M., Remache, J. and Sack, B. (2011). 'Large-scale asset purchases by the Federal Reserve: Did they work?', Federal Reserve Bank of New York Staff Reports 441.

Gurkaynak, R., Sack, B. and Swanson, E. (2005). 'Do actions speak louder than words? The response of asset prices to monetary policy actions and statements', International Journal of Central Banking, vol. 1(1), pp. 55-93.

Hall, R. (2011). 'The long slump', American Economic Review, vol. 101(2), pp. 431-69.

Hamilton, J. and Wu, J. (2010). 'The effectiveness of alternative monetary policy tools in a zero lower bound environment', Working Paper, University of California at San Diego.

Harrison, R. (2010). 'Asset purchase policy at the effective lower bound for interest rates', Working Paper, Bank of England.

Justiniano, A., Primiceri, G. and Tambalotti, A. (2010). 'Investment shocks and business cycles', Journal of Monetary Economics, vol. 57(2), pp. 132-45.

Justiniano, A., Primiceri, G. and Tambalotti, A. (2011). 'Is there a trade-off between inflation and output stabilization?', Working Paper, Federal Reserve Bank of Chicago.

Kapetanios, G., Mumtaz, H., Stevens, I. and Theodoris, K. (2011). 'Assessing the economywide effects of quantitative easing', Working Paper, Bank of England.

Kozicki, S., Santor, E. and Suchanek, L. (2010). 'Central bank balance sheets and the long-term forward rates', Working Paper, Bank of Canada.

Krishnamurthy A. and Vissing-Jorgensen, A. (2011). 'The effects of quantitative easing on interest rates: Channels and implications for policy', Brookings Papers on Economic Activity, Fall 2011.

Neely, C. (2011). 'The large-scale asset purchases had large international effects', Federal 


\section{The Macroeconomic Effects of LSAP Programs}

Reserve Bank of Saint Louis Working Paper 2010-018D.

Smets, F. and Wouters, R. (2003). 'An estimated dynamic stochastic general equilibrium model of the Euro Area', Journal of the European Economic Association, vol. 1(5), pp. 1123-75.

Smets, F. and Wouters, R. (2007). 'Shocks and frictions in U.S. business cycles: A Bayesian DSGE approach', American Economic Review, vol. 97(3), pp. 586-606.

Swanson, E. (2011). 'Let's twist again: A high-frequency event-study analysis of Operation Twist and its implications for QE2', Federal Reserve Bank of San Francisco Working Paper 2011-08.

Vayanos, D. and Vila, J. (2009). 'A Preferred-Habitat Model of the Term Structure of Interest Rates', Working Paper, London School of Economics.

Wallace, N. (1981). 'A Modigliani-Miller theorem for open-market operations', American Economic Review, vol. 71, pp. 267-74.

Woodford, M. (1998). 'Doing without money: Controlling inflation in a post-monetary world', Review of Economic Dynamics, vol. 1, pp. 173-219.

Woodford, M. (2001). 'Fiscal requirements for price stability', Journal of Money, Credit and Banking, vol. 33, pp. 669-728. 


\section{The Macroeconomic Effects of LSAP Programs}

Table 1: Estimated Impact of LSAPs on the 10-Year Treasury Yield in the Literature.

\begin{tabular}{lcc}
\hline \hline Papers & Total Impact & Impact per $\$ 100$ Bil \\
\hline Hamilton and Wu (2010) & $-13 \mathrm{bp}$ & $-3 \mathrm{bp}$ \\
Doh (2010) & $-39 \mathrm{bp}$ & $-4 \mathrm{bp}$ \\
D'Amico and King (2010) & $-45 \mathrm{bp}$ & $-15 \mathrm{bp}$ \\
Bomfim and Meyer (2010) & $-60 \mathrm{bp}$ & $-3 \mathrm{bp}$ \\
Gagnon et al. (2011) & $-58 \mathrm{bp}$ to-91 bp & $-3 \mathrm{bp}$ to-5 bp \\
Neely (2011) & $-107 \mathrm{bp}$ & $-6 \mathrm{bp}$ \\
Krishnamurthy and Vissing-Jorgensen (2011) & $-33 \mathrm{bp}$ (LSAP2) & $-5 \mathrm{bp}$ \\
D'Amico et al. (2011) & $-55 \mathrm{bp}$ (LSAP2) & $-9 \mathrm{bp}$ \\
Swanson (2011) & $-15 \mathrm{bp}$ (Twist) \\
\hline \hline
\end{tabular}


The Macroeconomic Effects of LSAP Programs

Table 2: Parameter Prior and Posterior Distribution: Structural Parameters.

\begin{tabular}{cccccccccc}
\hline \hline & \multicolumn{9}{c}{ Prior } \\
& Dist & $5 \%$ & Median & $95 \%$ & Mode & Mean & $5 \%$ & Median & $95 \%$ \\
\hline $400 \gamma$ & $\mathrm{G}$ & 1.7382 & 2.4667 & 3.3752 & 1.9922 & 1.9867 & 1.5413 & 1.9805 & 2.4515 \\
$400 \pi$ & $\mathrm{G}$ & 1.2545 & 1.9585 & 2.8871 & 2.2404 & 2.1477 & 1.5075 & 2.1376 & 2.8237 \\
$400\left(\beta_{u}^{-1}-1\right)$ & $\mathrm{G}$ & 0.6272 & 0.9792 & 1.4436 & 0.4943 & 0.4890 & 0.3282 & 0.4828 & 0.6706 \\
$400 \zeta$ & $\mathrm{G}$ & 0.3913 & 0.7224 & 1.2029 & 0.4761 & 0.5127 & 0.2735 & 0.4968 & 0.8082 \\
$B^{L M V} / B$ & $\mathrm{G}$ & 0.6953 & 0.9867 & 1.3501 & 0.8222 & 0.8502 & 0.7164 & 0.8533 & 0.9712 \\
$S^{\prime \prime}$ & $\mathrm{G}$ & 2.5090 & 3.9170 & 5.7743 & 4.4277 & 4.8371 & 3.3764 & 4.7815 & 6.5330 \\
$a^{\prime \prime}$ & $\mathrm{G}$ & 0.0683 & 0.1836 & 0.3877 & 0.2093 & 0.2322 & 0.0994 & 0.2159 & 0.4189 \\
$h$ & $\mathrm{~B}$ & 0.4302 & 0.6029 & 0.7597 & 0.8370 & 0.7898 & 0.6421 & 0.8020 & 0.9007 \\
$\sigma_{u}$ & $\mathrm{G}$ & 0.6832 & 1.8360 & 3.8768 & 3.0151 & 3.4958 & 1.9891 & 3.3548 & 5.4795 \\
$\sigma_{r}$ & $\mathrm{G}$ & 0.6832 & 1.8360 & 3.8768 & 1.5635 & 2.2370 & 0.8692 & 2.0825 & 4.1268 \\
$100 \zeta^{\prime}$ & $\mathrm{G}$ & 0.3067 & 1.2846 & 3.4294 & 0.2420 & 0.3763 & 0.0862 & 0.3274 & 0.8257 \\
$\omega_{u}$ & $\mathrm{~B}$ & 0.3214 & 0.7334 & 0.9646 & 0.9832 & 0.9322 & 0.8237 & 0.9468 & 0.9934 \\
$\Xi^{u} / \Xi^{r}$ & $\mathrm{G}$ & 0.3416 & 0.9180 & 1.9384 & 0.7917 & 1.1403 & 0.4537 & 1.0730 & 2.0683 \\
$C^{u} / C^{r}$ & $\mathrm{G}$ & 0.3416 & 0.9180 & 1.9384 & 0.7641 & 1.0533 & 0.3921 & 0.9760 & 1.9747 \\
$\chi_{w u}$ & $\mathrm{~B}$ & 0.2486 & 0.6143 & 0.9024 & 0.5170 & 0.5566 & 0.2825 & 0.5611 & 0.8187 \\
$\nu$ & $\mathrm{G}$ & 1.2545 & 1.9585 & 2.8871 & 1.6814 & 1.9658 & 1.2518 & 1.9295 & 2.7996 \\
$\zeta_{w}$ & $\mathrm{~B}$ & 0.3351 & 0.5000 & 0.6649 & 0.6860 & 0.7309 & 0.6292 & 0.7342 & 0.8205 \\
$\zeta_{p}$ & $\mathrm{~B}$ & 0.3351 & 0.5000 & 0.6649 & 0.9260 & 0.9287 & 0.9116 & 0.9288 & 0.9452 \\
$\phi_{T}$ & $\mathrm{G}$ & 0.7825 & 1.4448 & 2.4058 & 1.2660 & 1.3147 & 0.6890 & 1.2543 & 2.1216 \\
$\rho_{r}$ & $\mathrm{~B}$ & 0.5242 & 0.7068 & 0.8525 & 0.8547 & 0.8556 & 0.8182 & 0.8565 & 0.8903 \\
$\phi_{\pi}$ & $\mathrm{G}$ & 1.0164 & 1.7026 & 2.6453 & 1.5644 & 1.6090 & 1.3706 & 1.5979 & 1.8866 \\
$\phi_{y}$ & $\mathrm{G}$ & 0.1366 & 0.3672 & 0.7754 & 0.2975 & 0.3295 & 0.2487 & 0.3251 & 0.4247 \\
\hline \hline
\end{tabular}


The Macroeconomic Effects of LSAP Programs

Table 3: Parameter Prior and Posterior Distribution: Shock Process Parameters.

\begin{tabular}{cccccccccc}
\hline \hline & & \multicolumn{3}{c}{ Prior } & \multicolumn{5}{c}{ Posterior } \\
& Dist & $5 \%$ & Median & $95 \%$ & Mode & Mean & $5 \%$ & Median & $95 \%$ \\
\hline$\rho_{z}$ & B & 0.0976 & 0.3857 & 0.7514 & 0.1286 & 0.1486 & 0.0448 & 0.1430 & 0.2706 \\
$\rho_{\mu}$ & B & 0.5701 & 0.7595 & 0.8971 & 0.8293 & 0.8477 & 0.7906 & 0.8489 & 0.8998 \\
$\rho_{b}$ & B & 0.5701 & 0.7595 & 0.8971 & 0.9603 & 0.9597 & 0.9388 & 0.9614 & 0.9764 \\
$\rho_{\phi}$ & B & 0.5701 & 0.7595 & 0.8971 & 0.5200 & 0.5063 & 0.3767 & 0.5074 & 0.6345 \\
$\rho_{B}$ & B & 0.6146 & 0.8135 & 0.9389 & 0.9773 & 0.9652 & 0.9396 & 0.9659 & 0.9880 \\
$\rho_{\zeta}$ & B & 0.6146 & 0.8135 & 0.9389 & 0.9614 & 0.9402 & 0.9012 & 0.9426 & 0.9700 \\
$\rho_{g}$ & B & 0.5701 & 0.7595 & 0.8971 & 0.7581 & 0.7397 & 0.5542 & 0.7491 & 0.8943 \\
$\sigma_{z}$ & IG1 & 0.1663 & 0.3433 & 1.2367 & 0.7426 & 0.7624 & 0.6742 & 0.7588 & 0.8634 \\
$\sigma_{\lambda_{f}}$ & IG1 & 0.1663 & 0.3433 & 1.2367 & 1.6306 & 1.9235 & 1.1103 & 1.7930 & 3.1600 \\
$\sigma_{\mu}$ & IG1 & 0.1663 & 0.3433 & 1.2367 & 2.8430 & 3.0102 & 2.2984 & 2.9725 & 3.8662 \\
$\sigma_{b}$ & IG1 & 0.1663 & 0.3433 & 1.2367 & 3.0703 & 3.7799 & 2.2957 & 3.5860 & 5.8901 \\
$\sigma_{\phi}$ & IG1 & 0.1663 & 0.3433 & 1.2367 & 0.4518 & 0.9048 & 0.3100 & 0.7628 & 1.9982 \\
$\sigma_{B}$ & IG1 & 0.1663 & 0.3433 & 1.2367 & 0.3686 & 0.3656 & 0.2930 & 0.3578 & 0.4660 \\
$\sigma_{T}$ & IG1 & 0.1663 & 0.3433 & 1.2367 & 0.2348 & 0.5521 & 0.1670 & 0.3457 & 1.3682 \\
$\sigma_{m}$ & IG1 & 0.0819 & 0.1700 & 0.6217 & 0.1130 & 0.1167 & 0.1019 & 0.1161 & 0.1335 \\
$\sigma_{\zeta}$ & IG1 & 0.0819 & 0.1700 & 0.6217 & 0.2137 & 0.2667 & 0.1900 & 0.2592 & 0.3694 \\
$\sigma_{g}$ & IG1 & 0.1663 & 0.3433 & 1.2367 & 0.2439 & 0.3894 & 0.1688 & 0.3429 & 0.7619 \\
\hline \hline
\end{tabular}


The Macroeconomic Effects of LSAP Programs

Fig. 1: Simulated Path of the Market Value of Long-Term Debt.

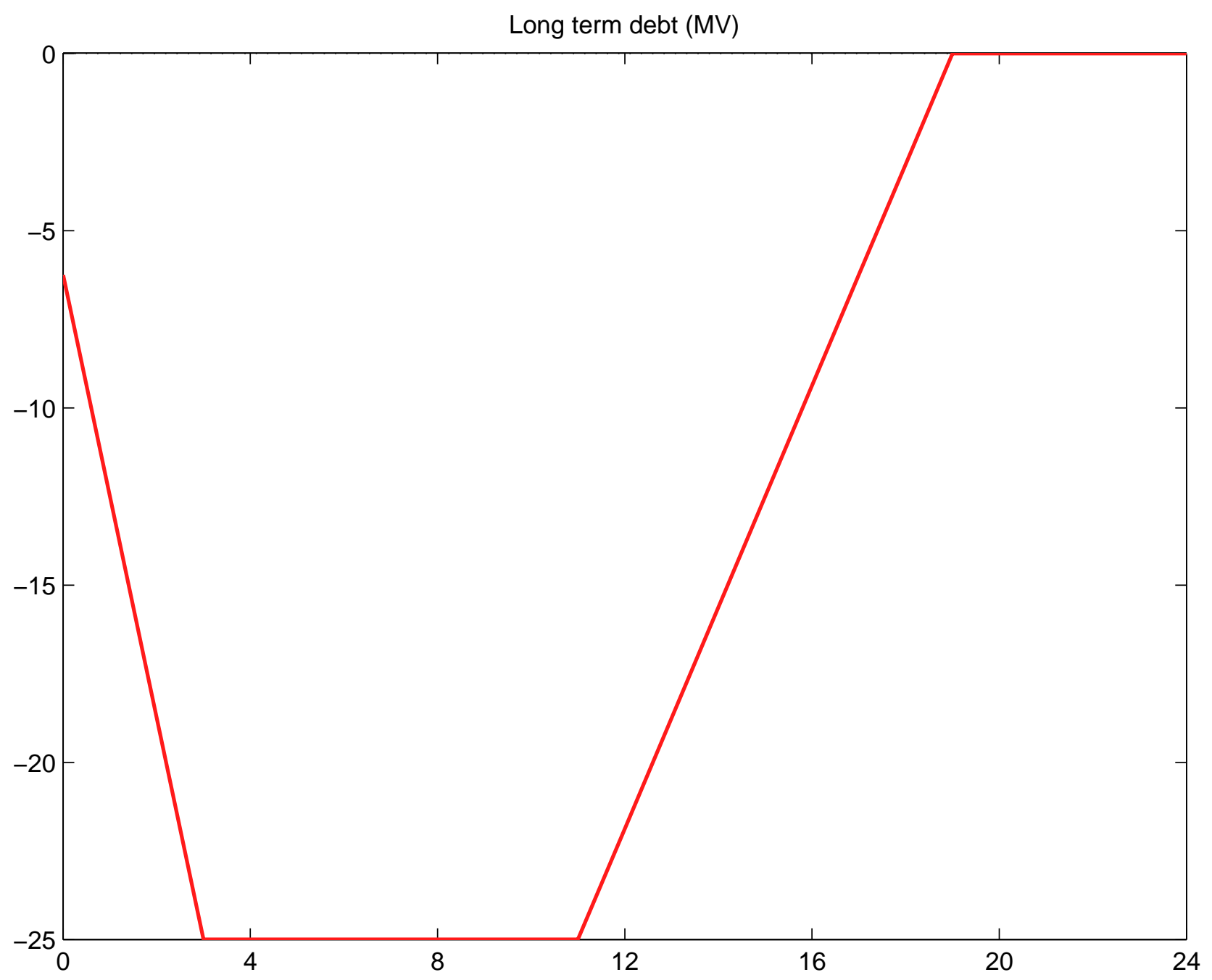


The Macroeconomic Effects of LSAP Programs

Fig. 2: Responses to Calibrated LSAP II Experiment at the Prior Distribution.
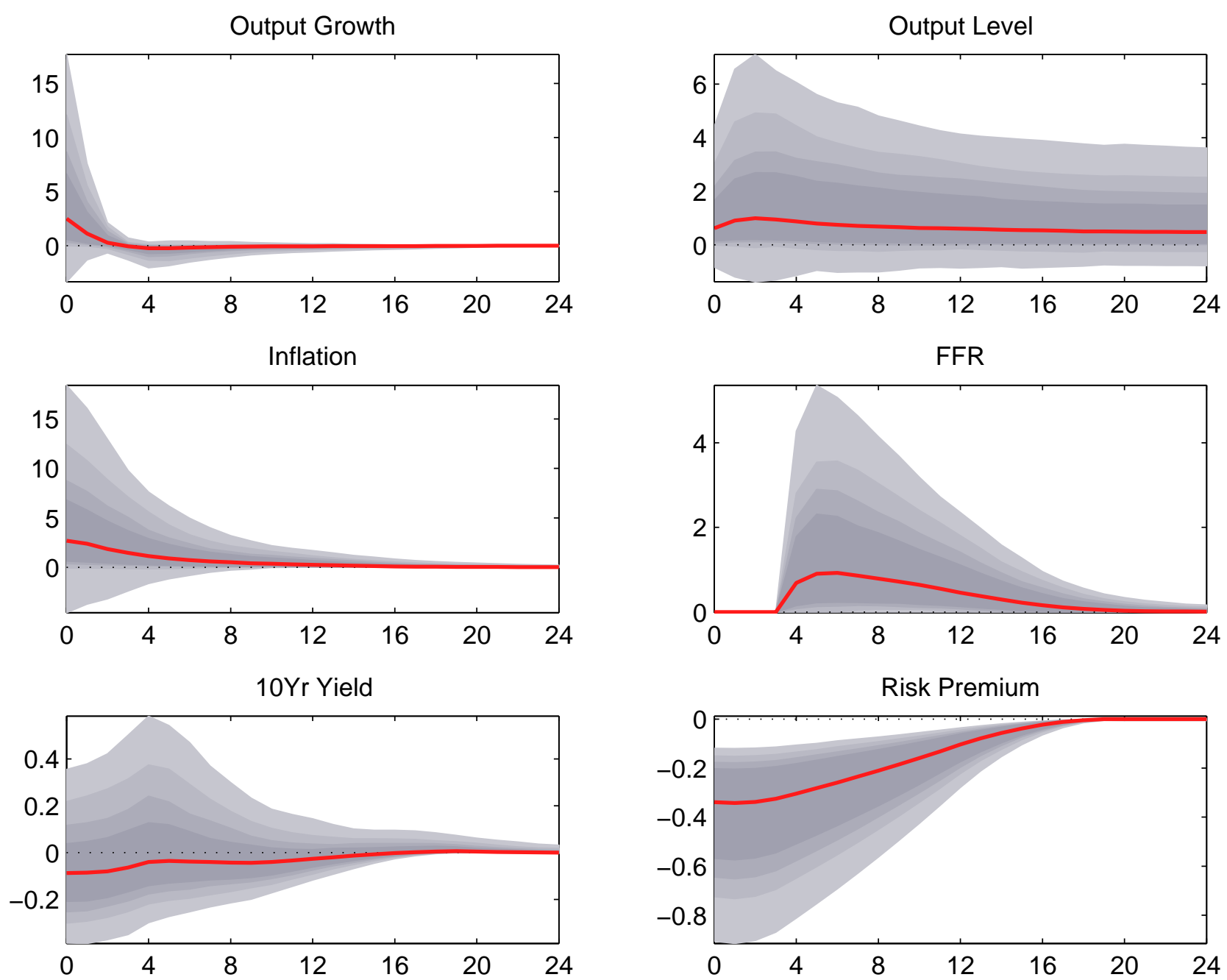

Risk Premium

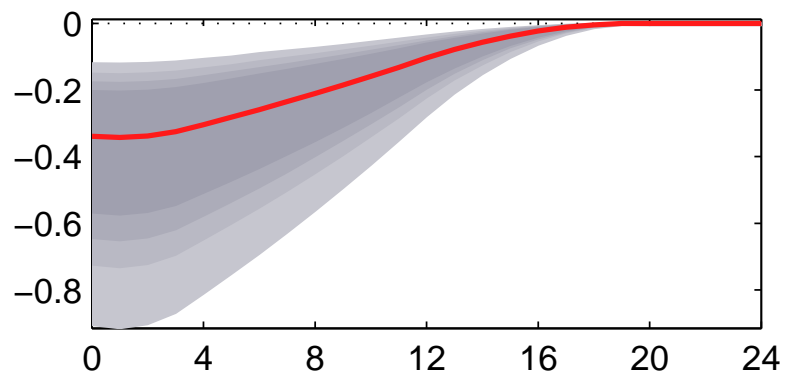


The Macroeconomic Effects of LSAP Programs

Fig. 3: Responses to Calibrated LSAP II Experiment at the Posterior Distribution.
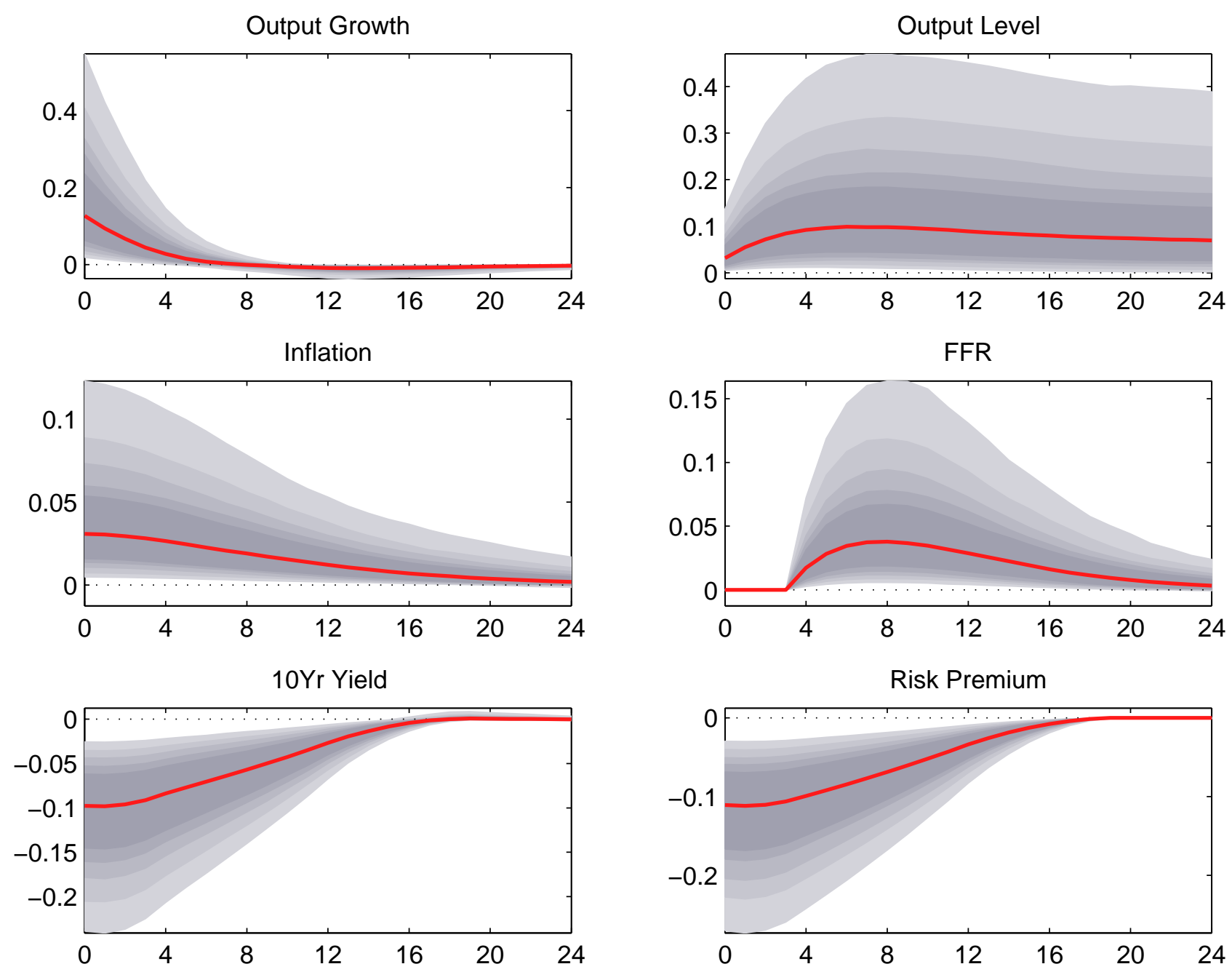
Fig. 4: Responses to LSAP II Experiment with (dashed blue line) and without (continuous red line) ZLB Commitment.
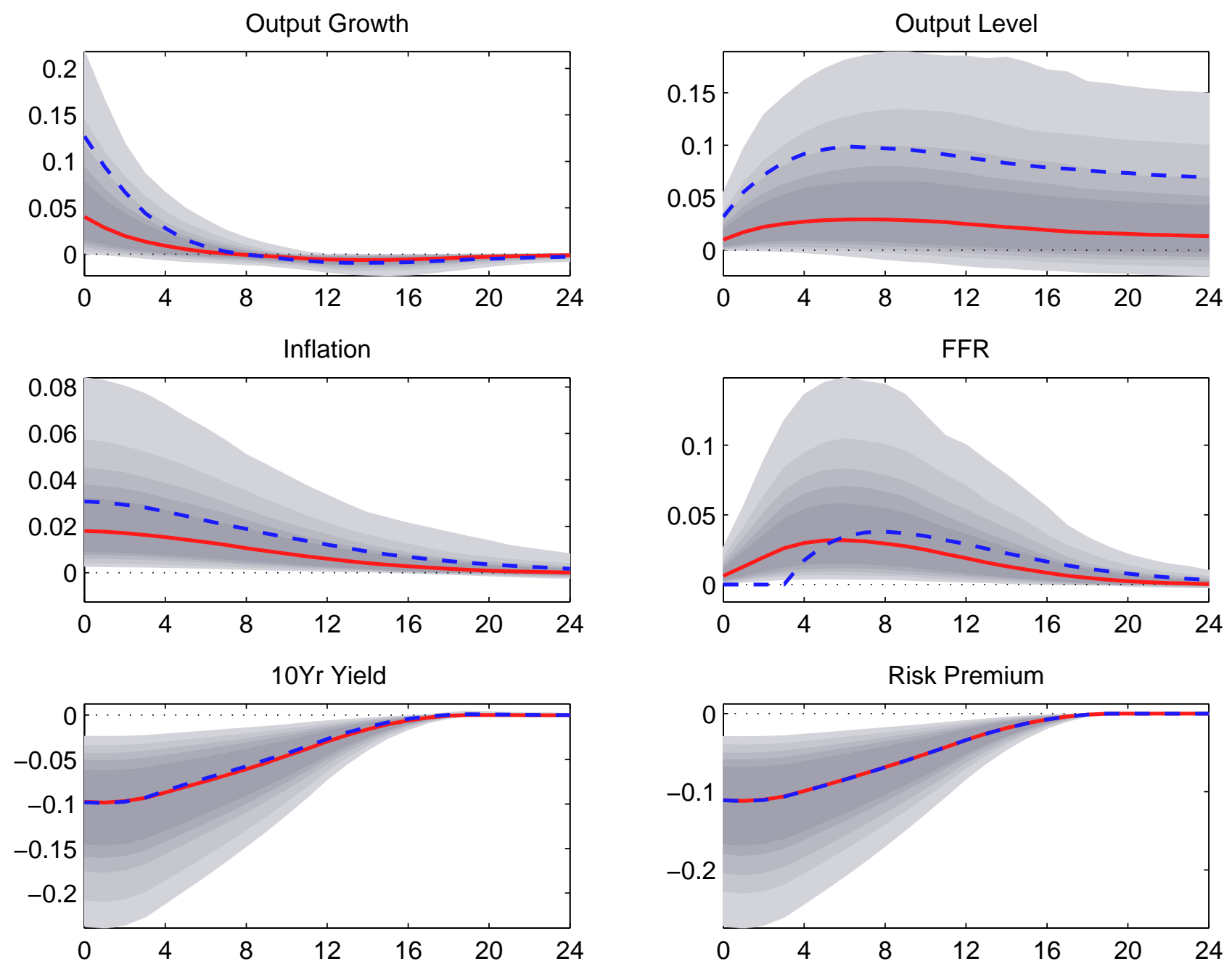
Fig. 5: Responses to an Annualised 25 bp Innovation to the FFR (continuous red line), Compared to the Baseline LSAP II Experiment (dashed blue line).
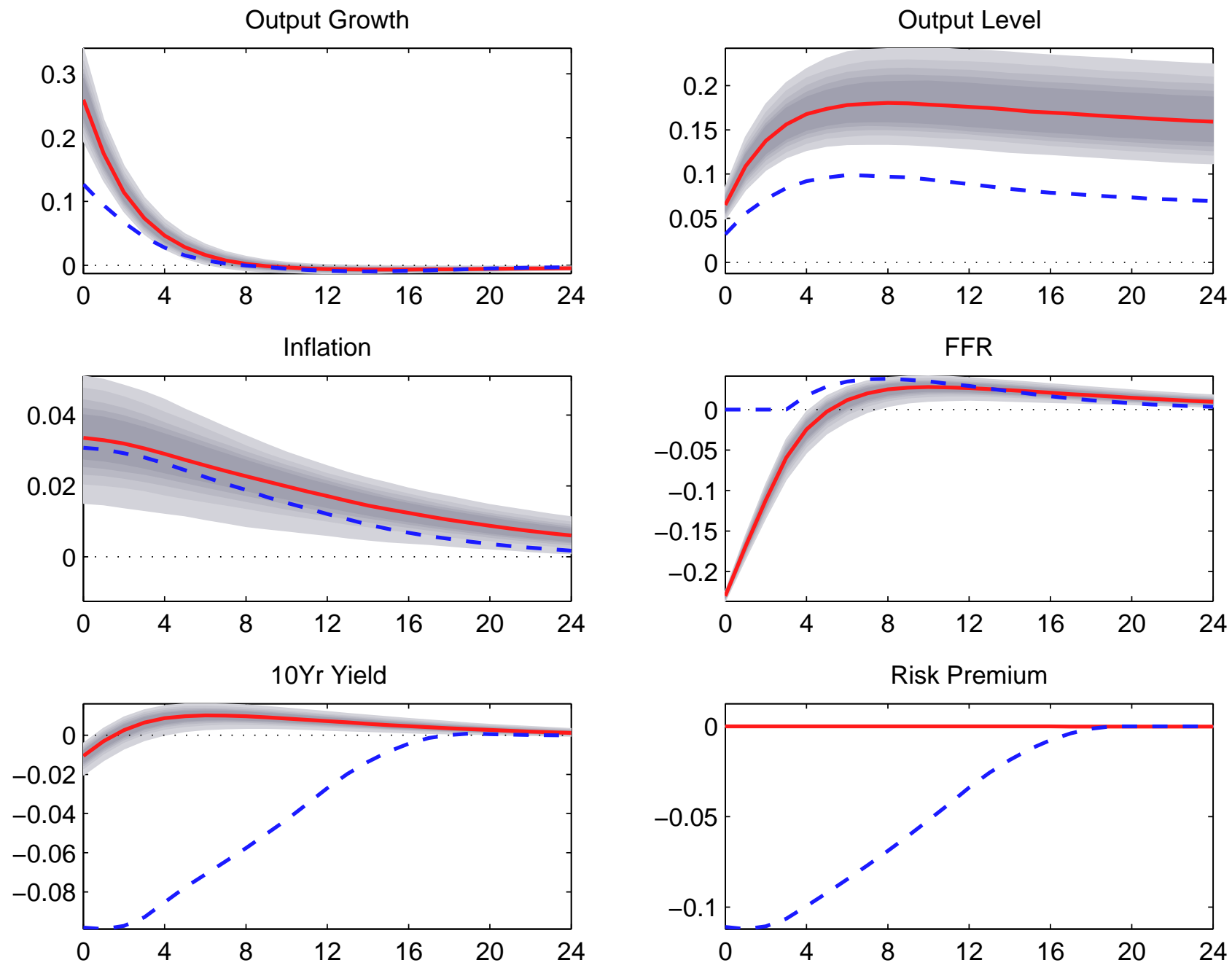